\title{
Rare presentation of a symptomatic primary neuroendocrine tumour of small bowel
}

\section{mesentery}

1. Tousif Kabir ${ }^{1,2}$

2. Michael Issa ${ }^{1}$

3. Graham Starkey ${ }^{1}$

${ }^{1}$ Hepatopancreatobiliary and Transplant Surgery, Department of Surgery, Austin Hospital, 145 Studley Road, Heidelberg, Victoria 3084

${ }^{2}$ Department of General Surgery, Sengkang General Hospital, 110 Sengkang E Way, Singapore 544886

\section{Corresponding author:}

Tousif Kabir

Consultant

Hepatopancreatobiliary service

Department of General Surgery

Sengkang General Hospital, Singapore 544886

E-mail: tousif.kabir@singhealth.com.sg

Contact: +6590095054

The corresponding author is not a recipient of any research scholarship.

This paper is not based on a previous communication to a society or meeting;

This is the author manuscript accepted for publication and has undergone full peer review but has not been through the copyediting, typesetting, pagination and proofreading process, which may lead to differences between this version and the Version of Record. Please cite this article as doi: 10.1111/ans.16431

This article is protected by copyright. All rights reserved. 
Word count:744

Number of figures: 3

Number of tables: 0

\section{Report:}

A 72-year old lady, previously well, presented with non-specific abdominal discomfort of a few weeks' duration. She did not have any flushing, diarrhoea, or shortness of breath. Physical examination was unremarkable with no cardiac wheeze or murmurs. Computed tomography (CT) scan revealed a 4cm mass in the small bowel mesentery with internal calcifications [Figure 1]. Gastroscopy and colonoscopy did not show any gastrointestinal tract (GIT) lesions. After discussion in a multidisciplinary tumor board meeting, a DOTATATE-Positron emission tomography (PET)/CT was performed which demonstrated intense activity in the mesenteric mass, consistent with a somatostatin receptor positive primary mesenteric neuroendocrine tumour (NET) [Figure 2]. There was no DOTATATEavid disease elsewhere in the body. Chromogranin A (CGA) levels were elevated at $261 \mathrm{U} / \mathrm{ml}$ (normal $<85 \mathrm{U} / \mathrm{ml}$ ), while urine 5-hydroxyindoleacetic acid (5-HIAA) levels were not checked preoperatively. Transthoracic echocardiography did not reveal any valvular heart disease. She was counseled for surgery during which the tumour was discovered to be located in the mid-jejunal mesentery, very close to the bowel wall. Hence, she underwent enbloc resection of the tumour with a segment of adjoining small bowel [Figure 3]. Her postoperative course was uneventful and she was discharged well 5 days after surgery. Histopathological examination confirmed a 45mm Grade 2 neuroendocrine tumour, with cells staining positively for chromogranin and synaptophysin with Ki67 index of 5-10\%, 
confirming a well-differentiated Stage IIA NET (pT2N0M0). She is currently being followed up with yearly review of symptoms, as well as monitoring of CGA levels and annual PETDOTATE scans.

Well-differentiated NETs, also called carcinoid tumours, are unusual lesions occurring in 1.9 persons per 100,000 annually [1]. They originate from somatostatin-producing enterochromaffin cells and typically arise from the gastrointestinal (small bowel (41.8\%), rectum (27.4\%), appendiceal (24.7\%)) and bronchopulmonary tracts [2]. Our patient presented with a primary NET of the mesentery which is extremely rare, as the majority (40 to $80 \%$ ) of mesenteric NETs usually develop secondary to metastasis from GIT lesions [3].

Affected individuals may present with a diverse range of non-specific symptoms, which makes diagnosis very challenging. Our patient had vague intermittent abdominal discomfort, which was likely due to chronic fibrosis of the mesentery caused by desmoplastic reaction incited by the tumour [4]. Approximately $10 \%$ of patients present with carcinoid syndrome which is manifested by diarrhea, wheezing and cutaneous flushing, due to liver metastasis or nodal involvement allowing serotonin to bypass normal hepatic metabolic degradation and enter the systemic circulation [5]. Other unusual manifestations include ectopic Cushing’s syndrome due to adrenocorticotropic hormone (ACTH) secretion [6]. Tethering and kinking of small bowel wall to the rigid mesentery may cause bowel obstruction [7]. In rare instances, large tumours may completely occlude mesenteric vessels resulting in regional portal hypertension or potentially fatal intestinal ischemia [7]. 
Elevated levels of 24-hour urine 5-HIAA and CGA are diagnostic for carcinoid tumours [8]. On CT scan, these lesions classically appear as soft tissue masses with a 'sunburst' appearance due to calcification and desmoplastic stranding [9]. DOTATATE-PET/CT scans are the imaging modality of choice for localizing primary tumours as well as any sites of metastasis. On microscopic examination, tumour cells have one of five growth patterns: insular, trabecular, glandular, undifferentiated or mixed [10]. NETs also have specific immunohistochemistry features and may stain positively for synaptophysin, CGA, cytokeratins and neuoron-specific enolase [3].

Where possible, complete surgical extirpation is the mainstay of therapy. Small tumours $<2 \mathrm{~cm}$ tend to be well-encapsulated, and can be carefully excised with closure of the mesenteric defect in order to prevent internal herniation of bowel loops in future [3]. Lesions which are located very near to the intestinal loops, as in our case, tumours encasing mesenteric vessels, or tumours $>2 \mathrm{~cm}$ which tend to have nodal involvement may require segmental bowel resection with lymph node dissection [3]. In rare instances, large tumours may involve the root of the small bowel mesentery and extend to the aorta and vena cava. Certain groups have described the use of partial abdominal evisceration and intestinal autotransplantation for management of these difficult lesions [7]. This is a radical procedure whereby the patient's entire small intestine is harvested en bloc and placed in cold preservative fluid to minimize warm ischemia injury. Subsequently the mesenteric mass is excised ex vivo, following which the intestine is autotransplanted back into the patient. Such 
aggressive surgeries should only be attempted in highly selected patients by expert surgeons in high-volume transplant units. For patients with unresectable metastatic disease, somatostatin analogs or palliative cytoreductive surgery may be beneficial for control of debilitating symptoms [5].

\section{Author contributions:}

1. Tousif Kabir: Conceptualisation, Data curation, Writing-original draft, review and editing.

2. Michael Issa: Conceptualisation, Writing-original draft, review and editing.

3. Graham Starkey: Conceptualisation, Supervision, Writing-review and editing.

\section{References:}

1. Pinchot SN, Holen K, Sippel RS, et al. Carcinoid tumors. Oncologist. 2008;13:12551269.

2. Modlin M, Lye KD, Kidd M. A 5-decade analysis of 13,715 carcinoid tumors. Cancer. 2003; 97:934-959.

3. Park I-S, Kye B-H, Kim H-S, et al. Primary mesenteric carcinoid tumor. J Korean Surg Soc. 2013;84:114-117.

4. Modlin IM, Shapiro MD, Kidd M: Carcinoid tumors and fibrosis: an association with no explanation. Am J Gastroenterol 2004, 99:2466-2478.

This article is protected by copyright. All rights reserved. 
5. Kvols, L.K., Moertel, C.G., O’Connell, M.J., Schutt, A.J., Rubin, J., Hahn, R.G.: Treatment of the malignant carcinoid syndrome: evaluation of a long-acting somatostatin analogue. N. Engl. J. Med. 315:663, 1986

6. Mashoori N, Rabani AH, Kazemeini AR. Ectopic Cushing's syndrome due to a mesenteric neuroendocrine tumor. Ann R Coll Surg Engl 2012;94:e251-3.

7. Kitchens WH, Elias N, Blaszkowsky LS, Cosimi AB, Hertl M. Partial abdominal evisceration and intestinal autotransplantation to resect a mesenteric carcinoid tumor. World J Surg Oncol 2011; 9: 11.

8. Maroun J, Kocha W, Kvols L, et al. Guidelines for the diagnosis and management of carcinoid tumours. Part 1: the gastrointestinal tract. A statement from a Canadian National Carcinoid Expert Group. Curr Oncol. 2006;13:67-76.

9. Karahan OI, Kahriman G, Yikilmaz A, Ozkan M, Bayram F. Gastrointestinal carcinoid tumors in rare locations: imaging findings. Clin Imaging 2006;30:278-82.

10. Woodside KJ, Townsend CM, Jr, Mark Evers B. Current management of gastrointestinal carcinoid tumors. J Gastrointest Surg 2004; 8:742-756.

\section{Legend}

1. Figure 1: Computed tomography (CT) scan with yellow arrow demonstrating a $4 \mathrm{~cm}$ well-circumscribed mass with internal calcifications in small bowel mesentery.

2. Figure 2: DOTATATE-Positron emission tomography (PET)/CT showing intense activity in the mesenteric mass consistent with a somatostatin receptor positive primary mesenteric neuroendocrine tumour (NET).

This article is protected by copyright. All rights reserved. 
3. Figure 3: Operative specimen containing mesenteric NET with adjoining segment of resected small bowel 


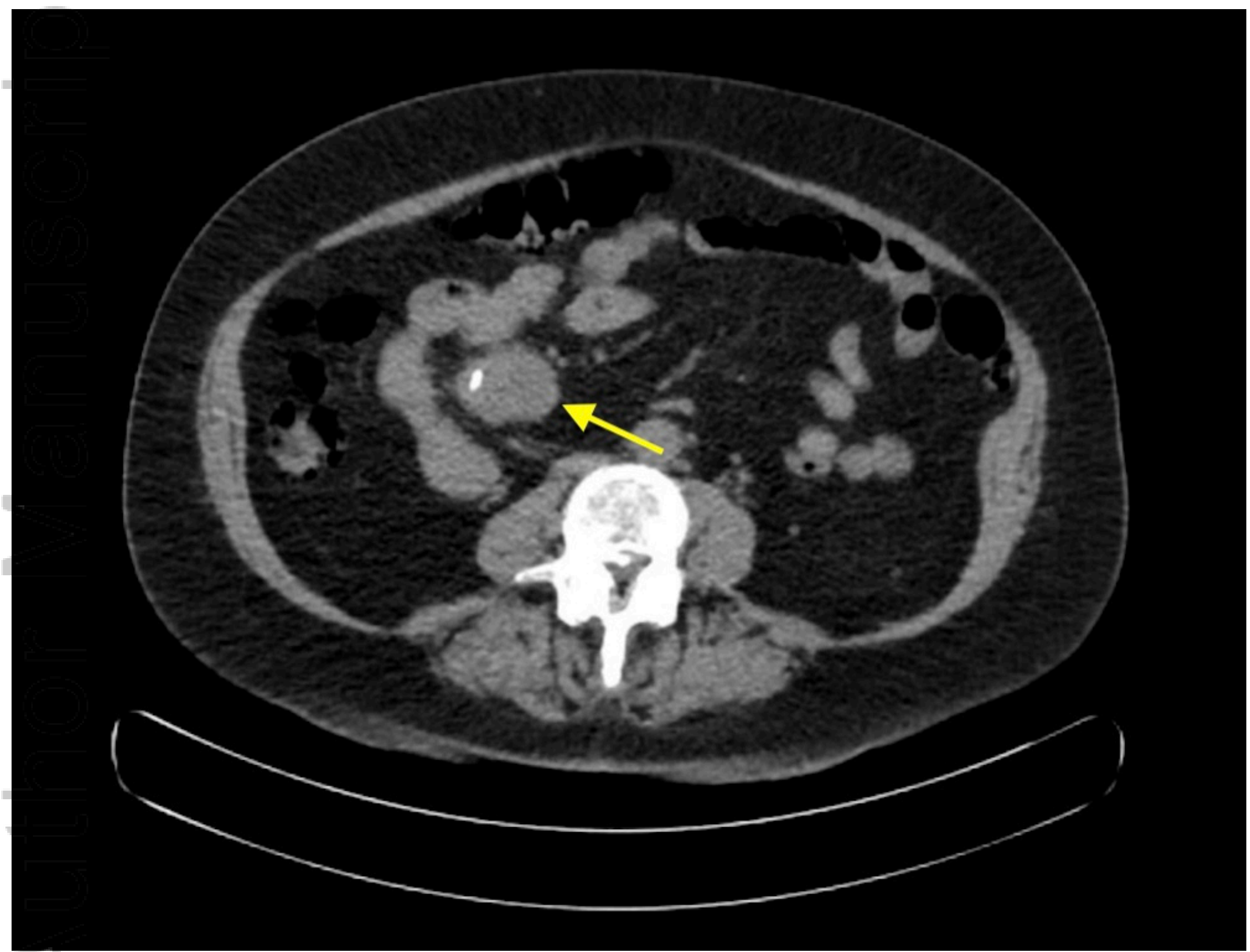

ANS_16431_Figure 1.png

This article is protected by copyright. All rights reserved. 


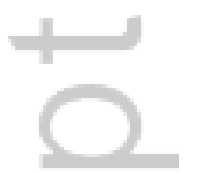

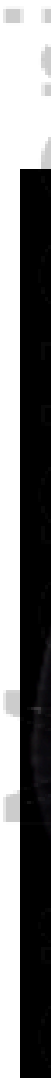

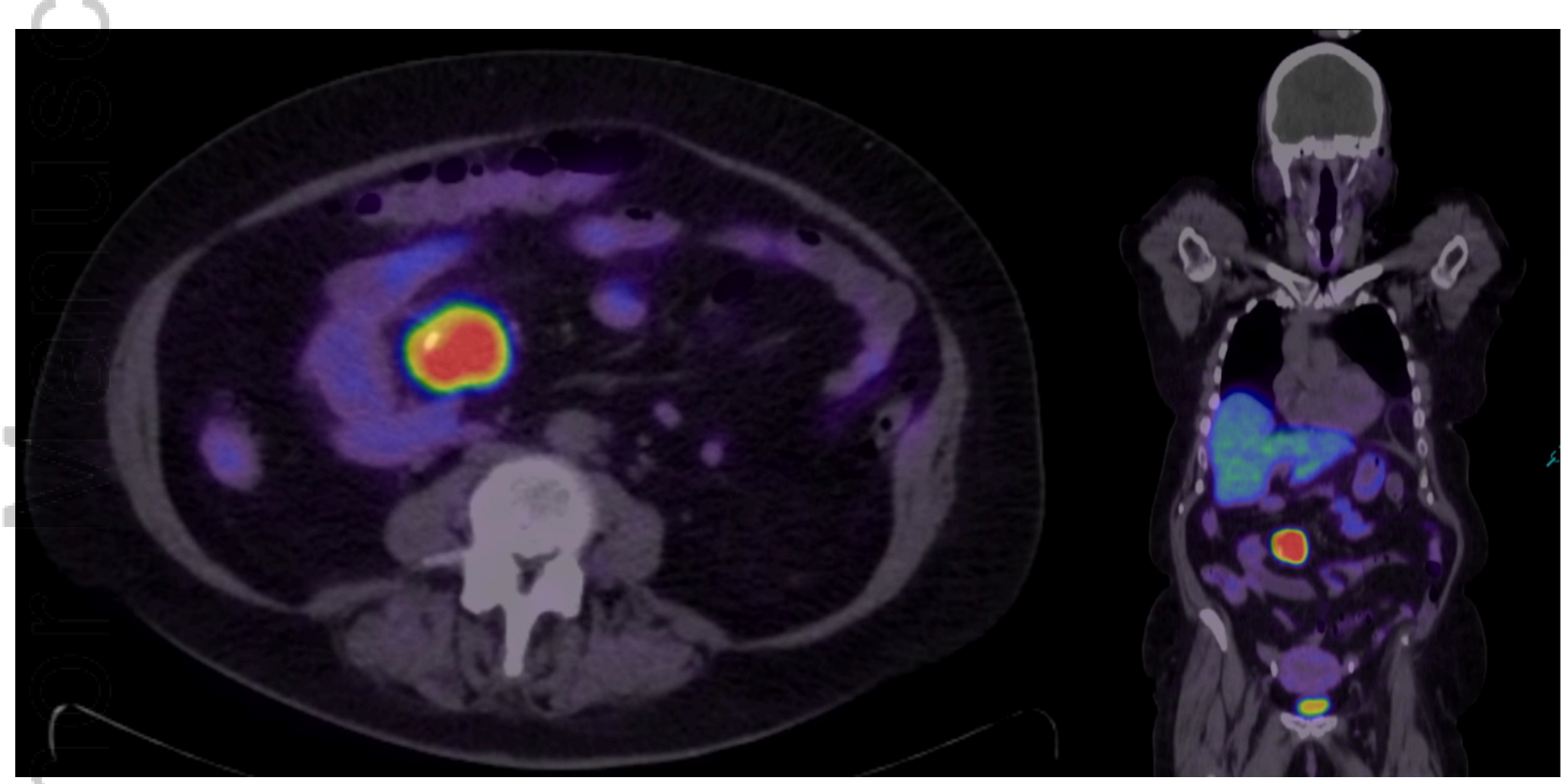

ANS_16431_Figure 2.png

This article is protected by copyright. All rights reserved. 


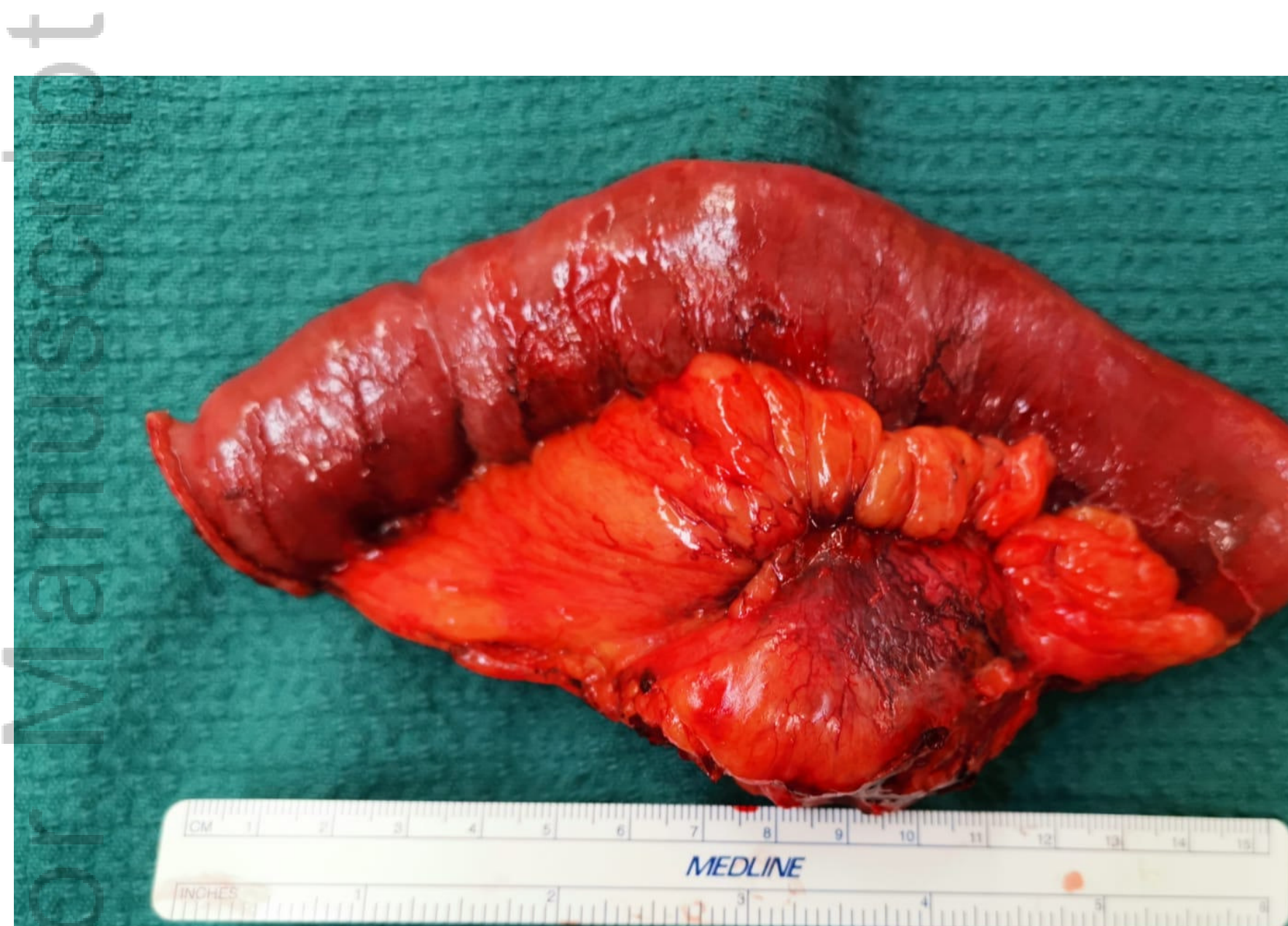




\section{University Library}

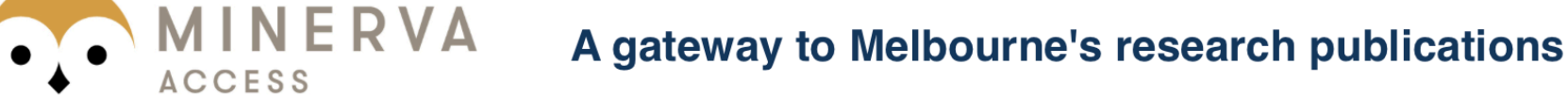

Minerva Access is the Institutional Repository of The University of Melbourne

Author/s:

Kabir, T;Issa, M;Starkey, G

Title:

Rare presentation of a symptomatic primary neuroendocrine tumour of small bowel mesentery

Date:

2020-11-06

Citation:

Kabir, T., Issa, M. \& Starkey, G. (2020). Rare presentation of a symptomatic primary neuroendocrine tumour of small bowel mesentery. ANZ JOURNAL OF SURGERY, 91 (6), pp.E403-E404. https://doi.org/10.1111/ans.16431.

Persistent Link:

http://hdl.handle.net/11343/276581 